\title{
RESEARCH
}

Open Access

\section{Determinants of species assemblages of insect pests in alpine forest ecosystems of western China}

\author{
Chun-Jing Wang ${ }^{1 \dagger}$, Rong Wang ${ }^{2 \dagger}$, Chun-Mei Yu ${ }^{3}$, Yongcuo Pubu ${ }^{4}$, Wan-Gui Sun ${ }^{3}$, Xiao-Feng Dang ${ }^{2}$, \\ Qiang-Feng $\mathrm{Li}^{1}$ and Ji-Zhong Wan ${ }^{1 *} \mathrm{~B}$
}

\begin{abstract}
Background: Insect pests are a significant threat to natural resources and social development. Modeling species assemblages of insect pests can predict spatiotemporal pest dynamics. However, research gaps remain regarding the mechanism for determining species assemblages of insect pests in alpine forest ecosystems. Here, we explored these determinants using a field investigation conducted for insect pests in a region of the Qinghai-Tibet Plateau. We assessed the species assemblages of insect pests in alpine forest ecosystems based on species co-occurrence patterns and species diversity (i.e., observed diversity, dark diversity, community completeness, and species pool). A probabilistic model was used to test for statistically significant pairwise patterns of species co-occurrence using the presence-absence matrix of pest species based on species interactions. We used ordinary least squares regression modeling to explore relationships between abiotic factors (i.e., climate factors and human influence) and species diversity.
\end{abstract}

Results: Positive pest species interactions and many association links can occur widely across different investigation sites and parts of plant hosts in alpine forest ecosystems. We detected high dark diversity and low community completeness of insect pests in alpine forest ecosystems. High temperature and precipitation could promote pest species diversity, particularly dark diversity and species pools. Human influence could drive high levels of pest species diversity and lead to dark diversity and species pools. Community completeness could be an effective indicator for insect pest risk assessment.

Conclusions: Our study provides new evidence for the determinants of insect pest species assemblages in alpine forest ecosystems from the perspectives of pest species interactions and abiotic factors. The findings of our study could reveal the mechanism for shaping species assemblages and support the prevention and control of insect pests in alpine forest ecosystems.

Keywords: Alpine forest ecosystems, Community completeness, Dark diversity, Insect pest, Species co-occurrence, Species diversity

\footnotetext{
* Correspondence: wan1276@163.com; wan1276@qhu.edu.cn

${ }^{\dagger}$ Chun-Jing Wang and Rong Wang contributed equally to this work.

${ }^{1}$ State Key Laboratory of Plateau Ecology and Agriculture, College of

Agriculture and Animal Husbandry, Qinghai University, Xining 810016, China

Full list of author information is available at the end of the article
}

Springer Open

(c) The Author(s). 2021 Open Access This article is licensed under a Creative Commons Attribution 4.0 International License, which permits use, sharing, adaptation, distribution and reproduction in any medium or format, as long as you give appropriate credit to the original author(s) and the source, provide a link to the Creative Commons licence, and indicate if changes were made. The images or other third party material in this article are included in the article's Creative Commons licence, unless indicated otherwise in a credit line to the material. If material is not included in the article's Creative Commons licence and your intended use is not permitted by statutory regulation or exceeds the permitted use, you will need to obtain permission directly from the copyright holder. To view a copy of this licence, visit http://creativecommons.org/licenses/by/4.0/. 


\section{Introduction}

The International Plant Protection Convention (IPPC) defined pests as species harmful to cultivated plants (agriculture, horticulture, and forestry), natural flora and plant products ranging from wood products and dried plant materials for handicrafts to fresh fruits and vegetables for consumption or processing and grains for food or feed (https://www.ippc.int). Insect pests are the surface feeders that damage foliage by chewing, piercing, or sucking and subsurface feeders, which can damage natural resources and social development across multiple ecosystems and regions worldwide (Clark and Kenna 2010; Savary et al. 2012; Venette 2017; Prather and Laws 2018; Cornelissen et al. 2019; Fei et al. 2019). Agricultural crops and forest resources are attacked by various insect pests, which pose a significant threat to global food security (Donatelli et al. 2017; Prather and Laws 2018; Fei et al. 2019). For example, insect pests (e.g., Coleoptera and Hymenoptera) can damage crops and food production (Lövei and Sunderland 1996; Cebolla et al. 2018). Furthermore, insect pests can threaten forest ecosystems jointly in many cases (Ji et al. 2011; Guo et al. 2019). Wood production declines because of insect pest damage (Sallé et al. 2014; Tiberi et al. 2016). Thus, the utilization efficiency of forest resources is reduced under a growing population. Hence, we should explore the mechanism of insect pest expansion in forest ecosystems.

Alpine forest ecosystems are more sensitive to environmental changes than other forest ecosystems in temperate and tropical areas (Chapin III and Körner 1994; Grabherr 2009; Minckley et al. 2012; Boix-Fayos et al. 2020). Rising temperatures can affect insect physiology and associated fitness and shift populations in space and time, thereby altering community interactions and composition (Shah et al. 2020). Johnson et al. (2010) showed that forest insect outbreaks are generally more common in alpine regions due to global warming. In the context of global ecological change, plant health may be among the most critical determinants of ecological processes influenced by precipitation and temperature variability in alpine forest ecosystems (Pautasso et al. 2012; Milosavljević et al. 2016; Boix-Fayos et al. 2020; Grünig et al. 2020; Lehmann et al. 2020). Numerous experimental and field studies (e.g., Frago et al. 2012; Grünig et al. 2020; Lehmann et al. 2020) have shown that plant-pest interactions might vary sharply with global environmental changes. Furthermore, insect pests always occur together in similar areas (Guo et al. 2019; Grünig et al. 2020). However, these previous studies (e.g., Logan et al. 2003; Johnson et al. 2010; Guo et al. 2019; Wang et al. 2021) have only concentrated on the effects of environmental changes on insect pests and have not considered their effects on pest species assemblages in alpine forest ecosystems. Modeling insect pest species assemblages can determine the risk of invasion (Worner and Gevrey 2006). Therefore, the relationships between patterns of species assemblages and environmental conditions in alpine forest ecosystems must be modeled to provide a reference for the prevention and control of insect pests in environment-sensitive areas. Here, we explored the determinants of insect pest species assemblages in alpine forest ecosystems to establish effective biological control systems.

Species diversity is a critical index for insect species assemblages. As suggested by Pärtel et al. (2013), four indices (i.e., observed diversity, dark diversity, community completeness, and species pool) should be used to quantify species diversity. The concept of dark diversity could be crucial for developing effective tools for biological risk (Ronk et al. 2017). Dark diversity implies the absence of suitable species from a species pool despite the appropriate biogeographic history and current ecological and environmental conditions for their presence (Pärtel et al. 2013; Ronk et al. 2017). In consideration of dark diversity, community completeness expresses how much of the species pool is realized within a local community. More complete communities should exert greater biotic resistance to biological invasion because they are more saturated and have greater resource depletion. To assess the potential of biological risk, we should predict the dark diversity and community completeness of insect pests (Pärtel et al. 2013; Ronk et al. 2017; Venette 2017). Biological control systems could be improved for potential insect pest risks based on the concepts of dark diversity and community completeness. The appropriate selection of environmental determinants of species diversity can improve the robustness of mechanistic insect pest forecast modeling, which is key to improving prevention and control (Magarey and Isard 2017).

Environmental changes (e.g., climatic changes) can drive the diversity of insect pests and shape their species assemblages in terrestrial ecosystems (Venette 2017; Cornelissen et al. 2019; Guo et al. 2019). Numerous studies have shown that abiotic factors (i.e., climate and human influence) are the main drivers of the species diversity and distribution of insect pests (Savary et al. 2012; Venette 2017; Hill et al. 2019; Jactel et al. 2019). The main effects of climate change drivers on forest insect performance and damage (e.g., insect survival and voltinism; Jactel et al. 2019; Grünig et al. 2020). Warmer temperatures can lead to a higher number of generations per year and higher survival, and severe droughts can weaken the ability of tree species to resist insect attack during (Baeten et al. 2019; Guo et al. 2019; Jactel et al. 2019; Grünig et al. 2020). In particular, strong human influences can increase the dispersal of insect pests worldwide (Cavers 2015). Thus, some insect pests with 
dark diversity may occur and then transfer the dark diversity of insect pest species to the observed diversity. Furthermore, species assemblages should form due to the positive interactions between different pest species in ecosystems (Cazelles et al. 2016; Nunez-Mir et al. 2017; D' Amen et al. 2018; Freilich et al. 2018; Grünig et al. 2020). Positive biotic interactions can shape spatial patterns of species aggregation (D' Amen et al. 2018). Hence, positive biotic interactions may be the determinants of species assemblages of insect pests in alpine forest ecosystems. Plant-pest interactions also play an important role in species assemblages (Frago et al. 2012; Grünig et al. 2020). Host species diversity ranges are related to species abundance distributions of insect pests (Guo et al. 2019; Rasche and Taylor 2019; Delbac et al. 2020). For example, tree species are likely to regulate the invasion of insect pests as their hosts (Guo et al. 2019). Hence, we sought to determine whether pest-pest and plant-pest interactions (i.e., biotic factors) coupled with environmental changes (i.e., abiotic factors) may be the determinants of species assemblages of insect pests in alpine forest ecosystems based on four indices (i.e., observed diversity, dark diversity, community completeness, and species pool). If we address this scientific issue, we could develop an effective indicator for insect pest risk assessment in alpine forest ecosystems based on relationships between abiotic factors and species diversity (Worner and Gevrey 2006).

Here, we proposed the following four hypotheses: 1) Hypothesis 1 (H1): insect pest species interactions may be positive in alpine forest ecosystems; 2) Hypothesis 2 $(\mathrm{H} 2)$ : dark diversity of insect pests may occur in alpine forest ecosystems; 3 ) Hypothesis 3 (H3): climatic factors and human influence may be the determinants of insect pest species diversity in alpine forest ecosystems; and 4) Hypothesis 4 (H4): the effects of abiotic factors on dark diversity and species pools may be larger than that on observed diversity. To test these four hypotheses, a field investigation was conducted for insect pests in the forest ecosystems of Qinghai Province, China, a region of the Qinghai-Tibet Plateau. We used multisite and multispecies measures of co-occurrence patterns to assess species assemblages in alpine forest ecosystems (Veech 2013; Griffith et al. 2016; Freilich et al. 2018). These measures were used to assess the interaction among different species (Veech 2013; Griffith et al. 2016). Co-occurrence methods are increasingly utilized in ecology to infer species interaction networks (Veech 2013; Griffith et al. 2016; Freilich et al. 2018). Understanding species cooccurrence patterns can help determine the causes and consequences of the species evolution, histories, coexistence mechanisms, competition, and environments that lead to the community structure and assemblages (Veech 2013; Freilich et al. 2018). The approach of Lewis et al. (2016) was applied to quantify insect pest species diversity based on four indices of species diversity: observed diversity, dark diversity, community completeness, and species pool.

\section{Materials and methods}

\section{Species data}

Qinghai Province, China, is a region of the QinghaiTibet Plateau from $103^{\circ} 04^{\prime}-116^{\circ} 33^{\prime} \mathrm{E}, 31^{\circ} 39^{\prime}-39^{\circ} 19^{\prime} \mathrm{N}$. Elevations range from 1650 to $6860 \mathrm{~m}$, and the average elevation is greater than $3000 \mathrm{~m}$. Qinghai Province includes representative alpine forest ecosystems in western China (Hou 2001). Our field investigation was conducted for 3 years in a network of sites based on vegetation density across the entire province. The field investigation sites are shown in Fig. 1. This field investigation was managed by the Qinghai Forestry and Grassland Administration for 3 years. These plots can cover most forests across most counties of Qinghai Province. In each county of Qinghai Province, we conducted fieldwork for insect pests in alpine forest ecosystems based on the Vegetation Atlas of China 1:1,000,000 from robust field investigations (Hou 2001; Zhang et al. 2007). Our fieldwork covered most of the vegetation recorded in the Vegetation Atlas of China at 1:1,000,000 in Qinghai Province. The plot size was approximately 3 acres. Specifically, the sizes and numbers of the plots were determined according to the ranges of host species in one specific forest ecosystem (Wang et al. 2021).

A given pest species can invade different parts of its plant hosts in alpine forest ecosystems. We identified the damage caused by a given insect pest based on the percentage of leaf loss, levels of stunting, and proportion of seedling death in host species in the field and conducted insect pest identification based on the knowledge of biocontrol and pest science experts. The experts assessed whether a specific insect species was a pest based on their knowledge and previous information from the first and second forestry pest survey projects in Qinghai Province, China. If the experts indicated that a given species was a pest, it was labeled as such. However, if insufficient evidence was available, a species was identified as a "potential insect pest". The insect pest species studied could invade alpine woody plants (e.g., Picea likiangensis, Populus cathayana, Picea crassifolia, Populus davidiana, and Hippophae rhamnoides) as harmful herbivores with high fecundity in forest ecosystems. Their invasion could lead to high percentages of leaf loss, stunting, and seedling death of host species.

In each plot, we investigated insect pests in more than 30 host plant individuals twice in the seasons of plant growth in one given year from 2014 to 2016. We recoded the scientific names of insect pest species, the parts of plant hosts invaded by insect pests, and the 

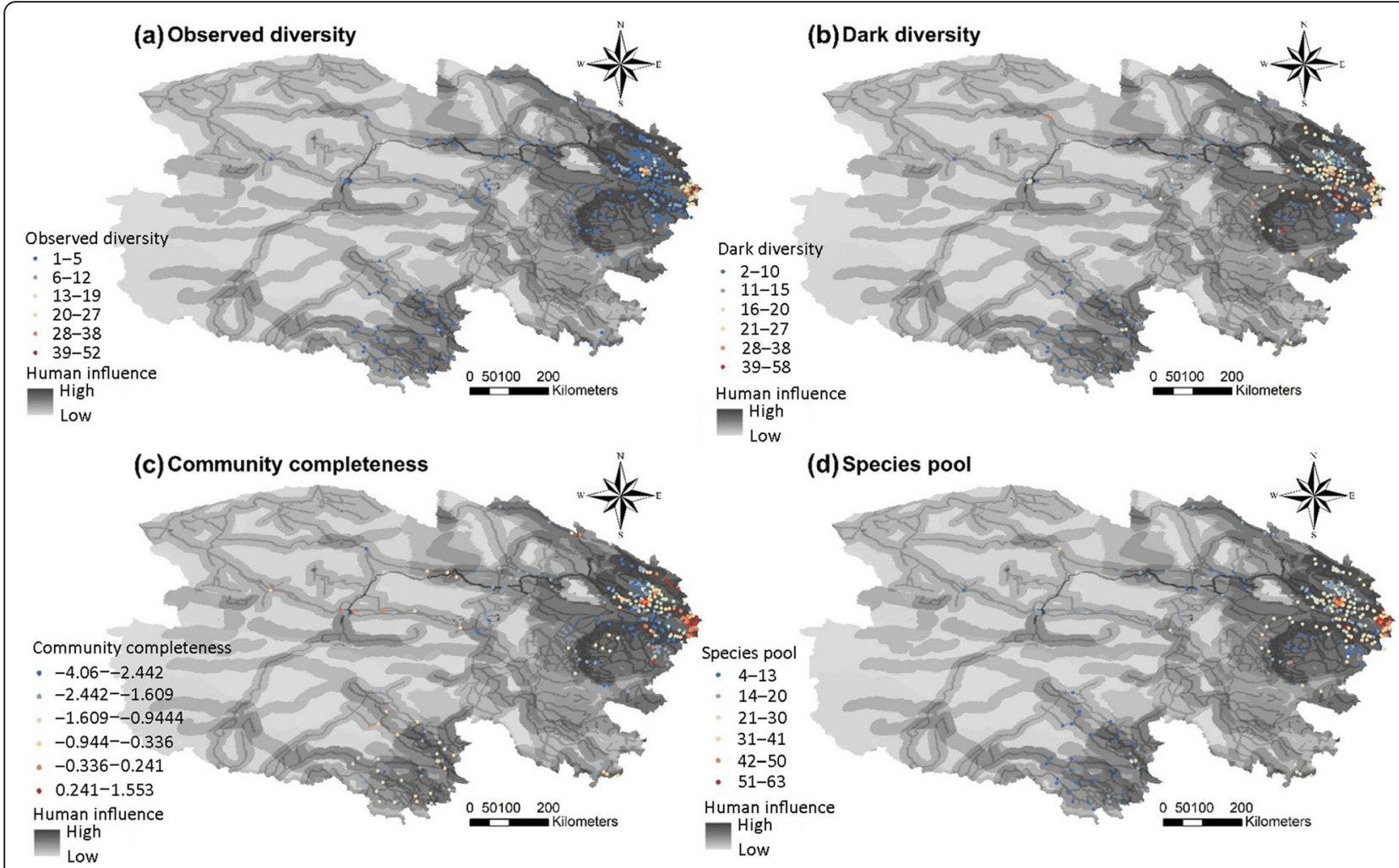

Fig. 1 Species diversity (i.e., observed diversity, dark diversity, community completeness, and species pool) of insect pests based on study sites in the forest ecosystems of Qinghai Province, China. The color of study sites (from blue to red) represents increasing levels of observed diversity (a), dark diversity (b), community completeness (c), and species pool (d) in the figures. The color of the figures from light to dark represented increasing levels of human influence

number of insect pest individuals in each plot (Wang et al. 2021). In total, 172 insect pest species were studied. These 172 insect pest species could invade five parts of their plant hosts (i.e., leaves, roots, seeds and fruits, trunks, and twigs) in forest ecosystems and pose a large threat to forest ecosystems in Qinghai Province, China.

\section{Abiotic factors}

Previous studies have shown that abiotic factors, namely, climate factors and human influence, can determine insect pest species assemblages (Savary et al. 2012; Hill et al. 2019; Jactel et al. 2019). Data on climate factors were downloaded with a spatial resolution of $0.5 \mathrm{arcmi}-$ nutes from the CHELSA (Climatologies at high resolution for the Earth's land surface areas) database (https://chelsa-climate.org/; Karger et al. 2017). We used 19 bioclimatic variables to assess the potential determinants of insect pest species assemblages in alpine forest ecosystems as follows: Bio1 = annual mean temperature; Bio2 $=$ mean diurnal range; Bio3 $=$ isothermality; Bio4 = temperature seasonality; $\operatorname{Bio} 5=\max$ temperature of warmest month; Bio6 $=$ min temperature of coldest month; Bio7 $=$ temperature annual range; $\mathrm{Bio} 8=$ mean temperature of wettest quarter; Bio9 $=$ mean temperature of driest quarter; Bio10 = mean temperature of warmest quarter; Bio11 = mean temperature of coldest quarter; Bio12 = annual precipitation; Bio13 $=$ precipitation of wettest month; Bio14 = precipitation of driest month; Bio15 = precipitation seasonality; Bio16 = precipitation of wettest quarter; Bio17 = precipitation of driest quarter; Bio18 $=$ precipitation of warmest quarter; and Bio19 = precipitation of coldest quarter (Karger et al. 2017). We used principal component analysis (PCA) to extract the first two principal components (PCs) that explained the majority of 19 climatic variables. The first two PCs explained $65.93 \%$ of the climatic variation. Climatic PC1 was positively related to Bio1, Bio5, Bio8, and Bio10, and climatic PC2 was positively related to Bio6, Bio11, Bio12 Bio13, and Bio16.

Sanderson et al. (2002) created a map of the Human Influence Index with a spatial resolution of 0.5 arcminutes based on human population pressure (population density), land use and infrastructure (built-up areas, night-time lighting, and land use/cover), as well as access (coastlines, roads, railroads, and navigable rivers; downloaded from https://sedac.ciesin.columbia.edu/data/ set/wildareas-v2-human-footprint-geographic). The human footprint (HF) was strictly related to the Human 
Influence Index, with a high human footprint index indicating the intactness, naturalness, and function of natural communities. We used a 0.5 -arcminute $(\sim 1 \mathrm{~km})$ resolution for all abiotic data. We extracted the data on abiotic factors (i.e., climate factors and human influence) based on the longitude and latitude of each field investigation site.

\section{Species co-occurrence pattern}

We used studies by Veech (2013) and Griffith et al. (2016) to analyze species co-occurrence patterns of insect pests in alpine forest ecosystems. A presence-absence matrix was built for analyzing the species co-occurrence patterns of insect pest species based on study sites. We used a probabilistic model to test for statistically significant pairwise patterns of species co-occurrence based on the concept of effect sizes using sites $\times$ species and parts $\times$ species matrices of insect pest species (Veech 2013; Griffith et al. 2016). The effect size was defined as the absolute difference between observed and expected co-occurrence for insect pests in alpine forest ecosystems based on comparison with unbiased null model distributions (Veech 2013; Griffith et al. 2016). The standardized range of effect size was from -1 to 1 and controlled for the number of sampling study sites (Veech 2013; Griffith et al. 2016). The effect size was used as an important index of interaction between two given species (Veech 2013; Cazelles et al. 2016; Freilich et al. 2018). We used the number of association links (i.e., the number of one given species with the other species with positive species interaction) and average effect size (i.e., the average values of effect sizes of association of one given species with the other species) to quantify the site-specific and part-specific interaction of the given species with the other species (Veech 2013; Freilich et al. 2018). Thus, the sitespecific and part-specific cooccurrence levels of insect pest species could be assessed by the interaction among different species based on the number of association links and average effect size (Veech 2013; Cazelles et al. 2016; Freilich et al. 2018).

\section{Species diversity}

We used the approach of Lewis et al. (2016) to quantify insect pest species diversity based on four indices: observed diversity, dark diversity, community completeness, and species pool. We calculated the number of pest species (i.e., species richness) for observed diversity at the study sites. We quantified dark diversity based on the species co-occurrence patterns across the forest ecosystems of Qinghai Province, China. The assessment of species co-occurrence patterns was based on the probability of a species occurring in an investigation site using the Beals index (Lewis et al. 2016). According to the sites $\times$ species matrix for pest species, the Beals index was correlated with species frequency; therefore, each species was assigned a threshold value for inclusion in dark diversity (Lewis et al. 2016). These thresholds were derived from each species' estimated probabilities of occurrence at sites where they were present, and they were set at the $5 \%$ quantile of those probabilities to omit outliers (Lewis et al. 2016). The details for dark diversity assessments were shared in the study by Lewis et al. (2016). We used the logarithmic ratio of observed and dark diversities to calculate the community completeness, and the species pool was the sum of the observed and dark diversities for a given study site, which indicated how much of the site-specific species pool was represented in local communities, i.e., the community completeness (Pärtel et al. 2013).

\section{Synthesis}

To test Hypothesis 1, we used ordinary least squares (OLS) regression modeling to explore the relationships between the number of association links and effect sizes for insect pests in forest ecosystems in Qinghai Province. We then compared the number of association links with positive, negative, and random effect sizes across 172 insect pest species. Following this, we applied Student's ttest to check the differences in the number of association links and effect size among the five parts of the plant hosts that were invaded (i.e., leaves, roots, seeds and fruits, trunks, and twigs) in the ecosystems studied. To test Hypothesis 2, we compared four indices for pest species diversity (i.e., observed diversity, dark diversity, community completeness, and species pool) across different study sites. We used ANOVA tests to check the differences between the observed and dark diversities at these sites. To test Hypothesis 3, we used OLS regression modeling to explore the relationships between the same pest species diversity indices used to test Hypothesis 2 and abiotic variables, such as climate factors (PCs) and human influence. A boosted regression tree (BRT) was used to explore the contribution of abiotic factors (Bio1-19 and human influence) to the formation of insect pest species assemblages in alpine forest ecosystems. To test Hypothesis 4, we examined the results of OLS regression modeling to find the relationships between pest species diversity and abiotic factors. All analyses were conducted in $\mathrm{R}$ (https://www.r-project.org/) and JMP 11.0 (https://www.jmp.com/zh_cn/home.html).

\section{Results}

We found that the effect sizes of species cooccurrence among insect pests were positive for 839 pairs, negative for 152 pairs, and random for 1175 pairs, as shown in the Supporting Information. The number of association links ranged from 1 to 93 and the effect sizes ranged from -0.007 to 0.021 across different insect pest species (Fig. 2). The largest number of association links was 93, 


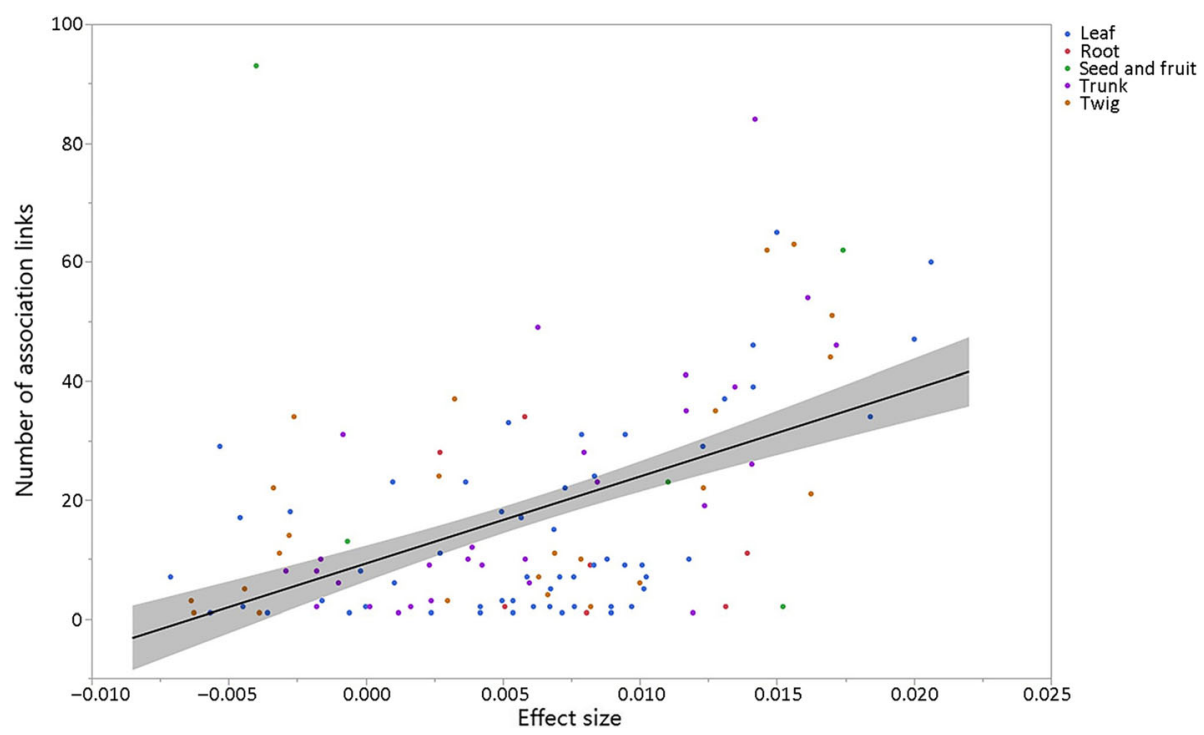

Fig. 2 The number of association links and effect sizes for insect pest species based on species co-occurrence analysis across different parts of plant hosts (i.e., leaves, roots, seeds and fruits, trunks, and twigs). There was a significant relationship between the number of association links and effect size in the forest ecosystems of Qinghai Province, China $\left(R^{2}=0.258 ; P<0.001\right)$. The line dash represents the $95 \%$ confidence intervals in regression modeling

and the largest effect size was 0.021 (Fig. 2). There was a significant relationship between the number of association links and the effect size across all insect pest species $(P<0.05$; Fig. 2). We found that $86,14,46$, and 60 pest species invaded the leaves, roots, trunks, and twigs, respectively (Fig. 2), and the average effect sizes were positive across the leaves, roots, seeds and fruits, trunks, and twigs (Fig. 3, details in the Supporting Information). We found that there were significant differences between seeds and fruit and the other parts (i.e., leaves and roots) for the number of association links $(P<0.05$; Table 1) and between twigs and trunks for the effect size $(P<0.05$; Fig. 3; Table 1$)$.

The observed diversity, dark diversity, community completeness, and species pool ranged from 1 to 52,2 to $58,-4.060$ to 1.553 , and 4 to 63 , respectively (Fig. 1 ). The areas with high species diversity, particularly dark diversity, community completeness, and species pool,

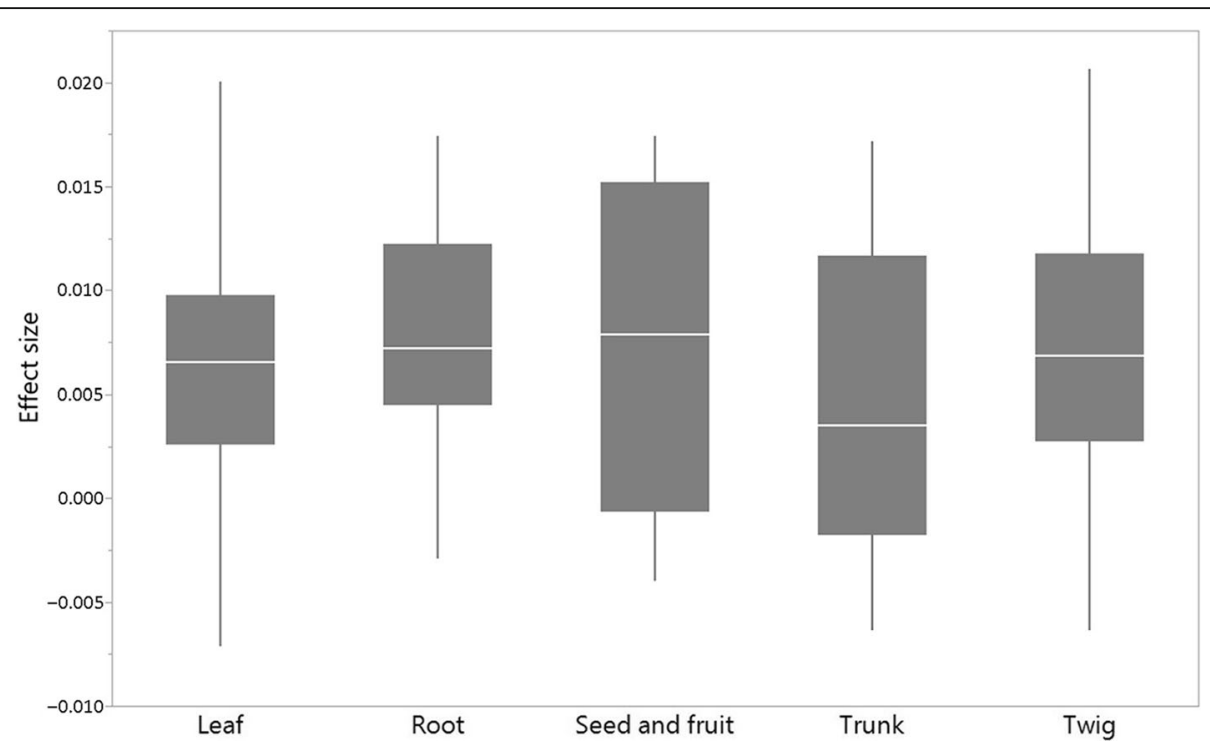

Fig. 3 Effect sizes for insect pests across five parts (i.e., leaves, roots, seeds and fruits, trunks, and twigs) of plant hosts in the forest ecosystems of Qinghai Province, China. The upper and lower bars represent the $95 \%$ confidence intervals of the contribution of environmental variables, and the lines represent the medium values of the contribution of environmental variables 
Table 1 Difference tests for the number of association links and effect sizes for insect pest species among five parts of plant hosts (i.e., leaves, roots, seeds and fruits, trunks, and twigs). Difference represents the minus values of mean number of association links and effect sizes between two specific parts of plant hosts (Part1 minus Part2). The results of this table were shown based on the pairs of two specific parts of plant hosts

\begin{tabular}{|c|c|c|c|c|c|}
\hline \multirow[t]{2}{*}{ Part1 } & \multirow[t]{2}{*}{ Part2 } & \multicolumn{2}{|c|}{ Number of association links } & \multicolumn{2}{|l|}{ Effect size } \\
\hline & & Difference & $P$-values & Difference & $P$-values \\
\hline Seed and fruit & Root & 19.929 & 0.023 & 0.000 & 0.931 \\
\hline Seed and fruit & Leaf & 15.925 & 0.032 & 0.002 & 0.551 \\
\hline Seed and fruit & Trunk & 14.264 & 0.063 & 0.004 & 0.183 \\
\hline Seed and fruit & Twig & 11.602 & 0.124 & 0.001 & 0.703 \\
\hline Twig & Root & 8.326 & 0.137 & 0.001 & 0.706 \\
\hline Trunk & Root & 5.665 & 0.325 & 0.003 & 0.102 \\
\hline Twig & Leaf & 4.323 & 0.173 & 0.001 & 0.624 \\
\hline Leaf & Root & 4.003 & 0.461 & 0.001 & 0.500 \\
\hline Twig & Trunk & 2.662 & 0.471 & 0.003 & 0.048 \\
\hline Trunk & Leaf & 1.661 & 0.629 & 0.002 & 0.095 \\
\hline
\end{tabular}

were distributed in the eastern forest ecosystems of Qinghai Province (Fig. 1). Dark diversity was significantly higher than the observed diversity for insect pests in the Qinghai forest ecosystems $(P<0.05$; Fig. 1$)$.

There were significant positive relationships between climatic PCs (i.e., PC1 and PC2) and pest species diversity indices $(P<0.05$; Fig. 4$)$. The effects of climatic PC1 on pest species diversity were higher than those of $\mathrm{PC} 2$ (Fig. 4). High temperatures and precipitation could result in high pest species diversity, particularly in terms of dark diversity and species pools (Fig. 4). The effects of human influence on pest species diversity were significantly positive according to all four indices and significantly greater than the effects of climate factors $(P<$ 0.05; Fig. 4). High temperatures, precipitation, and human influence could lead to high community completeness (Fig. 4). The annual mean temperature and temperature seasonality contributed the most to the species diversity indices for insect pests in the alpine forest ecosystems studied (Table 2).

The effects of human influence on pest species diversity were significantly larger than those of climate factors in Qinghai Province, China $(P<0.05$; Fig. 4). Furthermore, the effects of abiotic factors (i.e., climate factors and human influence) on the species pool were larger than the observed and dark species diversity (Fig. 4). However, the effects of abiotic factors on dark diversity were smaller than those on observed diversity (Fig. 4). All four indices of pest species diversity showed that the effect of abiotic factors on the species pool was the largest (Fig. 4).

\section{Discussion}

The determinants of insect pest species assemblages in alpine forest ecosystems were evaluated based on species interactions and the effects of abiotic factors on pest species diversity to improve the prevention and control of pest invasions. Species interactions shaped species assemblages in alpine forest ecosystems. Our results showed that the abiotic factors examined determined the levels of observed diversity, dark diversity, community completeness, and species pool of insect pests in the ecosystems studied. The results of our study, which provides a mechanism for shaping insect species assemblages for pest management, showed that high dark diversity and low community completeness among insect pests in alpine forest ecosystems were key factors for improving pest management in alpine forests. The insect pest species studied had great potential to generate large levels of leaf loss, stunting, and seedling death in their host species, thereby posing a threat to woody plant species in alpine forests. Thus, ecosystems with high dark diversity and low community completeness of insect pests present a high risk of damage. Therefore, high dark diversity and low community completeness of insect pests in alpine forest ecosystems can support pest management in alpine forests.

\section{Pest species interactions}

Our results described above and the significant relationship observed between the number of association links and effect size for insect pest species indicated that positive pest species interactions were detected widely in alpine forest ecosystems. Furthermore, the number of positive effect sizes of species co-occurrence was higher than the number of negative effect sizes. The high number of association links (i.e., 839 pairs) suggest that insect pest species could invade similar areas jointly. These pest species invaded the leaves, trunks, and twigs of plants. Species interactions were mainly the 


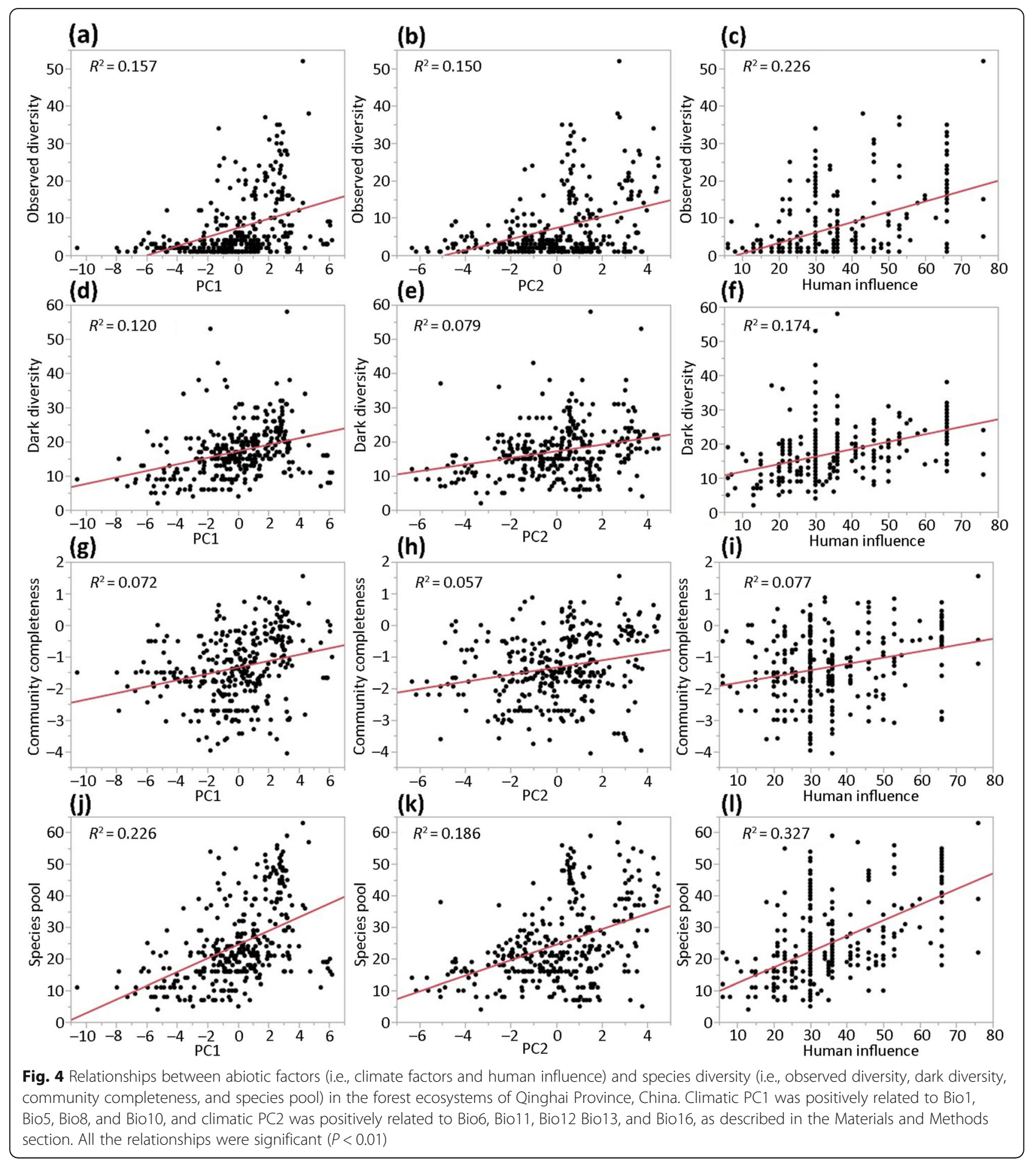

determinant of species assemblages of insect pests in alpine forest ecosystems. However, 1175 association pairs were random for species co-occurrence among insect pests, indicating that there were no associations among some specific insect pest species in alpine forest ecosystems. Most of the nonrandom positive and negative species associations could be attributed to environmental filtering and/or dispersal limitations (D' Amen et al. 2018; Freilich et al. 2018; Blanchet et al. 2020). Biological interpretations, including dispersal limitations, environmental niche differences, and biotic interactions, cannot contribute to insect pest species assemblages in alpine forest ecosystems (D' Amen et al. 2018; Blanchet et al. 2020). Therefore, our study could provide evidence that 
Table 2 The contribution of abiotic factors (Bio1-19, and human influence) to observed diversity, dark diversity, community completeness, and species pool for insect pests based on Boosted Regression Tree (BRT). The codes of abiotic factors were shown in Materials and Methods

\begin{tabular}{|c|c|c|c|c|}
\hline Factor & Observed diversity & Dark diversity & Community completeness & Species pool \\
\hline$\overline{B i o 1}$ & 7.214 & 9.109 & 6.683 & 7.494 \\
\hline $\mathrm{Bio} 2$ & 2.995 & 3.078 & 3.800 & 3.322 \\
\hline $\mathrm{Bio3}$ & 7.900 & 4.862 & 9.952 & 6.142 \\
\hline Bio4 & 9.691 & 10.452 & 9.326 & 8.530 \\
\hline Bio5 & 7.364 & 7.709 & 9.687 & 6.403 \\
\hline Bio6 & 6.367 & 5.675 & 7.300 & 6.285 \\
\hline Bio7 & 4.808 & 3.616 & 4.527 & 4.720 \\
\hline Bio8 & 2.946 & 8.580 & 3.247 & 3.935 \\
\hline Bio9 & 6.882 & 7.807 & 5.694 & 7.993 \\
\hline Bio10 & 2.349 & 1.101 & 4.129 & 2.842 \\
\hline Bio11 & 6.358 & 8.200 & 4.393 & 5.426 \\
\hline Bio12 & 6.492 & 5.006 & 5.323 & 6.820 \\
\hline Bio13 & 3.460 & 2.718 & 2.505 & 2.828 \\
\hline Bio14 & 0.137 & 0.439 & 0.209 & 0.440 \\
\hline Bio15 & 5.977 & 5.570 & 6.064 & 5.612 \\
\hline Bio16 & 5.536 & 3.337 & 3.573 & 5.771 \\
\hline Bio17 & 1.209 & 0.575 & 1.319 & 0.963 \\
\hline Bio18 & 6.158 & 3.980 & 5.591 & 6.386 \\
\hline Bio19 & 0.687 & 0.191 & 0.987 & 0.604 \\
\hline $\mathrm{HF}$ & 5.467 & 7.994 & 5.689 & 7.483 \\
\hline
\end{tabular}

species interactions among insect pests may not occur in some cases for forest ecosystems.

Species co-occurrence patterns are an important indicator of species assemblages of insect pests across different spatial scales (Horner-Devine et al. 2007; Veech 2013; Cazelles et al. 2016; D' Amen et al. 2018; Freilich et al. 2018). Species interactions are the basic driver of species assemblages in alpine areas (Cazelles et al. 2016; D' Amen et al. 2018; Freilich et al. 2018). The biotic resistance hypothesis and fluctuating resource hypothesis could support our findings (Maron and Vilà, 2001; Müller-Schärer et al. 2004; Sax et al. 2007). Biotic interactions with native species can affect the establishment and spread of invasive plant species, and alpine forest ecosystems provide hosts that could promote the invasion of pest species (Nunez-Mir et al. 2017; Venette 2017; Guo et al. 2019; Grünig et al. 2020). Tree diversity, as an effective biotic factor, plays an important role in insect pest species assemblages in alpine regions (Guyot et al. 2019; Guo et al. 2019; Jactel et al. 2021). Higher tree species diversity may lead to higher resistance to insect pest invasion (Guyot et al. 2016, 2019; Jactel et al. 2021). Several main mechanisms have been proposed to explain associational resistance effects (Guyot et al. 2016, 2019; Jactel et al. 2019, 2021; Poeydebat et al.
2021). In a diverse host community, host individuals are more likely isolated from one another due to the presence of nonhost species (Guo et al. 2019; Jactel et al. 2021). Furthermore, low diversity resident communities with low biomass have a weak ability to resist the establishment of pest invaders in alpine forest ecosystems (Forister et al. 2012; Nunez-Mir et al. 2017; Fei et al. 2019). Thus, negative relationships may occur between tree species diversity and insect pest species diversity. Furthermore, heterospecific neighborhoods favor a greater abundance of herbivore natural enemies (predators and parasitoids) because of the increased availability of habitats or alternative resources, which leads to reduced herbivore abundance and damage (Guo et al. 2019; Guyot et al. 2019; Jactel et al. 2021). Hence, pest species community assemblages can invade alpine forest ecosystems widely due to their hosts and weak competition.

The fluctuating resource hypothesis assumes that an invading species has access to available resources (e.g., light, nutrients, and water for pests) and greater success in invading a community if it does not encounter intense competition for resources from resident species (Klapwijk et al. 2016; Pearson et al. 2018; Guo et al. 2019). Limited resource availability causes competition in 
various parts of plants as pests compete for resources (Sequeira and Mackauer 1992; Eyles et al. 2010). However, we found that the average effect sizes were positive across all five invaded parts of plant hosts (i.e., leaves, roots, seeds and fruits, trunks, and twigs) in the forest ecosystems of Qinghai Province, China, indicating that there were positive species interactions for insect pests across different parts of plant hosts in alpine forest ecosystems. The results on the number of association links and effect size indicated that there were significant differences in species interactions for insect pests across the different invaded parts of hosts for insect pests. Host resource availability could affect species interactions among insect pests in cultivated and forest ecosystems (Eyles et al. 2010; Klapwijk et al. 2016; Nunez-Mir et al. 2017; Pearson et al. 2018; Delbac et al. 2020). Plant host parts (e.g., seeds and fruits) provide sufficient resources for insect pests in alpine forest ecosystems (Eyles et al. 2010; Guo et al. 2019). Therefore, species cooccurrences of insect pests could occur widely in alpine forest ecosystems due to the availability of resources from their hosts. Thus, species assemblages of insect pests are determined by invaded parts of plant hosts in alpine forest ecosystems, which indicates that the invaded parts of plant hosts should be monitored depending on different assemblages of insect pests.

\section{Effects of abiotic factors on species diversity}

We found that the areas with high levels of dark diversity, community completeness, and species pools were distributed in the eastern forest ecosystems of Qinghai Province, China, and dark diversity was significantly higher than the observed diversity for insect pests in the forest ecosystems. This finding indicates a high potential invasion risk in alpine forest ecosystems (Pärtel et al. 2013; Ronk et al. 2017). Dark diversity is the set of absent species from a study site but present in the surrounding region and potentially able to inhabit the same ecological conditions (Lewis et al. 2017; Pärtel et al. 2013). High dark diversity may lead to insect pest outbreaks in alpine forest ecosystems (Lewis et al. 2017; Ronk et al. 2017), and this high potential risk may be caused by abiotic factors (i.e., climate factors and human influence; Gallardo et al. 2015; Kulhanek et al. 2011). We found that the effects of abiotic factors on the species pool were larger than the effects of observed and dark species diversity, indicating that insect pest invasion could occur widely in alpine forest ecosystems (Pärtel et al. 2013; Lewis et al. 2017; Ronk et al. 2017). It is necessary to determine the predictors of pest species diversity to prevent and control pest risk (Gurr et al. 2017; Lewis et al. 2017).

Climatic factors, particularly annual mean temperature and temperature seasonality, are the main drivers of insect pest species assemblages in alpine forest ecosystems. Our analysis showed that high temperatures and precipitation levels could lead to high pest species diversity, particularly in terms of dark diversity and species pools. Numerous studies have shown that climatic factors are the determinants of observed insect diversity at large scales (Venette 2017; Grünig et al. 2020; Lehmann et al. 2020; Schneider et al. 2021; Wang et al. 2021). Similarly, our study provides evidence of the effects of climatic conditions on dark diversity and species pools for insect pests in alpine forest ecosystems. Temperature shifts can directly influence insect populations by modifying the rates of development, reproduction, and mortality, while reductions in host tree resistance caused by changes in precipitation can contribute to the growth of insect populations (Bale et al. 2002; Amarasekare and Savage 2012; Régnière et al. 2012; Schneider et al. 2021; Wang et al. 2021). Suboptimal tree growth conditions and reduced tree vigor can also lead to outbreaks of forest insect attacks due to changes in temperature and precipitation (Waring \& O'Hara 2005). Therefore, climatic variability (i.e., shifts in temperature and precipitation) can result in high dark diversity and species pools. We found that the effects of climatic PC1 on the pest species diversity indices studied were higher than those of $\mathrm{PC} 2$, indicating that temperature changes should be monitored to prevent invasions of and otherwise control insect pests in alpine forest ecosystems. Insect pests can benefit from increasing minimum winter temperatures (Schneider et al. 2021), with a particular risk of invasions likely due to the effects of temperature changes on dark diversity.

Our results show that the effects of human influence on pest species diversity were significantly positive, indicating that it was the main driver in alpine forest ecosystems. Disturbance can promote invasion success for some insects in native habitats, and human influence might be associated with both climatic niche emptiness and expansion (Eschtruth and Battles 2008; GonzálezMoreno et al. 2015; Hill et al. 2017, 2019). Anthropogenic changes to the landscape create niche opportunities for insect pests (Cariveau and Winfree 2015; Hill et al. 2017). Small patches can lead to novel environments for insect pests within a broader landscape (Cariveau and Winfree 2015). The novel niche hypothesis suggests that increased environmental heterogeneity may favor the expansion of pest species and coexistence with their hosts and competitors via niche differences (Lu et al. 2007; Cariveau and Winfree 2015; Hill et al. 2017). Hence, human influence could drive the high observed diversity of insect pests. Our study provides evidence that human influence leads to high levels of dark diversity and species pools of insect pests in alpine forest ecosystems due to novel niches under environmental 
changes. Human activities (e.g., agricultural development and urbanization) could increase the invasion risk of insect pests in alpine forest ecosystems by impacting dark diversity and species pools (Sanderson et al. 2002; Gallardo et al. 2015; Hill et al. 2019).

The concept of insect pest community completeness could contribute to biodiversity and ecosystem conservation in alpine forest ecosystems (Pärtel et al. 2013; Ronk et al. 2017). The community completeness of insect pests was low in the forest ecosystems of Qinghai Province, China, because of changes in temperature, precipitation, and human influence. Community completeness is an interface between observed and dark diversities within the species pool (Pärtel et al. 2013). Low levels of community completeness of insect pests could indicate increasing pest invasion risk in alpine forest ecosystems (Pärtel et al. 2013; Ronk et al. 2017). Positive species interactions and suitable abiotic factors favored high dark diversity and species pools; therefore, alpine forest ecosystems were exposed to insect pest invasion (Lewis et al. 2017; Pärtel et al. 2013; Ronk et al. 2017). A community completeness index could be an effective indicator for macroscale risk assessments of insect pests in alpine forest ecosystems (Pärtel et al. 2013; Ronk et al. 2017). High invasion risk could occur widely in areas with low community completeness for insect pests (Pärtel et al. 2013; Ronk et al. 2017). Our results indicate that the effect of long-term changes in temperature, precipitation, and human influence on insect pests should be monitored in alpine forest ecosystems.

\section{Conclusions}

Our study provides new evidence for the determinants of insect pest species assemblages in alpine forest ecosystems from the perspectives of pest species interactions and abiotic factors. Species interactions shape species assemblages due to the positive effect sizes of species co-occurrence between insect pests and the high number of association links. Positive species interactions determined the species assemblages of insect pests in alpine forest ecosystems. Furthermore, climate factors and human influence were the abiotic determinants of species assemblages because high temperatures, precipitation, and human influence increased the observed diversity, dark diversity, and species pools in alpine forest ecosystems. Community completeness could be an effective indicator for insect pest risk assessments in alpine forest ecosystems due to the positive relationships between human influence and community completeness. This study will be useful for supporting the prevention and control of insect pests and provides new information for species assemblages in alpine forest ecosystems.

\section{Supplementary Information}

The online version contains supplementary material available at https://doi. org/10.1186/s40663-021-00351-7.

\section{Additional file 1:.}

Acknowledgements

Many thanks for the helpful comments from the editor and reviewers on the improvement of our manuscript. We thank the conservation staff from the government bodies, universities, and research institutes who have made the database on insect pest species in Qinghai Province, China, and have conducted the projects of the first and second forestry pest survey of Qinghai Province, China. We acknowledge Pablo A Marquet's Lab for supporting our work.

\section{Authors' contributions}

Chun-Jing Wang, Rong Wang and Ji-Zhong Wan conceived the ideas and designed the study; Rong Wang and Chun-Mei Yu collected and managed the data; Chun-Mei Yu, Yongcuo Pubu, Xiao-Peng Dang, Wan-Gui Sun, and Qiang-Feng Liconducted the fieldwork; Chun-Jing Wang, Rong Wang, and Ji-Zhong Wan collaborated with the statistical analysis and interpretation of data; Chun-Jing Wang and Ji-Zhong Wan wrote the first version of the manuscript with substantial contribution from Rong Wang. All authors contributed to subsequent drafts and gave final approval for publication.

\section{Funding}

This work has been supported by the National Natural Science Foundation of China (Nos. 31800449 and 31800464), and the project of the third forestry pest survey of Qinghai Province, China.

\section{Availability of data and materials}

All environmental data used in this manuscript are publicly available and sources described in the text with the exception of field investigation data on insect pests, which are maintained by Forest Pest Control and Quarantine Station of Qinghai Province, China with compliance of confidentiality laws in China. All the resulting data are available in Supporting Information.

\section{Declarations}

Ethics approval and consent to participate

All the authors have approved the manuscript and agreed with submission to your esteemed journal.

Consent for publication

Not applicable.

\section{Competing interests}

There are no conflicts of interest to declare.

\section{Author details}

${ }^{1}$ State Key Laboratory of Plateau Ecology and Agriculture, College of Agriculture and Animal Husbandry, Qinghai University, Xining 810016, China. ${ }^{2}$ Forestry and Grassland Planning Institute of Qinghai Province, Xining 810016, China. ${ }^{3}$ Forest Pest Control and Quarantine Station of Qinghai Province, Xining 810016, China. ${ }^{4}$ Forestry Station of Yushu City, Yushu 815000 , China.

Received: 14 July 2021 Accepted: 14 October 2021

Published online: 16 November 2021

\section{References}

Amarasekare P, Savage V (2012) A framework for elucidating the temperature dependence of fitness. Am Nat 179:178-191

Baeten L, Bruelheide H, van der Plas F, Kambach S, Ratcliffe S, Jucker T, Allan E, Ampoorter E, Barbaro L, Bastias CC, Bauhus J, Benavides R, Bonal D, Bouriaud O, Bussotti F, Carnol M, Castagneyrol B, Charbonnier Y, Chećko E, Coomes DA, Dahlgren J, Dawud SM, De Wandeler H, Domisch T, Finér L, Fischer M, Fotelli M, Gessler A, Grossiord C, Guyot V, Hättenschwiler S, Jactel H, Jaroszewicz B, Joly FX, Koricheva J, Lehtonen A, Müller S, Muys B, Nguyen D, Pollastrini M, Radoglou K, Raulund-Rasmussen K, Ruiz-Benito P, Selvi F, Stenlid 
J, Valladares F, Vesterdal L, Verheyen K, Wirth C, Zavala MA, Scherer-Lorenzen M (2019) Identifying the tree species compositions that maximize ecosystem functioning in European forests. J Appl Ecol 56:733-744

Bale JS, Masters GJ, Hodkinson ID, Awmack C, Bezemer TM, Brown VK, Butterfield J, Buse A, Coulson JC, Farrar J, Good JEG, Harrington R, Hartley S, Jones TH, Lindroth RL, Press MC, Symrnioudis I, Watt AD, Whittaker JB (2002) Herbivory in global climate change research: direct effects of rising temperature on insect herbivores. Glob Chang Biol 8:1-16

Blanchet FG, Cazelles K, Gravel D (2020) Co-occurrence is not evidence of ecological interactions. Ecol Lett 23:1050-1063

Boix-Fayos C, Boerboom LG, Janssen R, Martínez-Mena M, Almagro M, PérezCutillas P, Eekhout JPC, Castillo V, De Vente J (2020) Mountain ecosystem services affected by land use changes and hydrological control works in Mediterranean catchments. Ecosyst Serv 44:101136

Cariveau DP, Winfree R (2015) Causes of variation in wild bee responses to anthropogenic drivers. Curr Opin Insect Sci 10:104-109

Cavers S (2015) Evolution, ecology and tree health: finding ways to prepare Britain's forests for future threats. Forestry 88:1-2

Cazelles K, Araújo MB, Mouquet N, Gravel D (2016) A theory for species cooccurrence in interaction networks. Theory Ecol 9:39-48

Cebolla R, Vanaclocha P, Urbaneja A, Tena A (2018) Overstinging by hymenopteran parasitoids causes mutilation and surplus killing of hosts. J Pest Sci 91:327-339

Chapin FS III, Körner C (1994) Arctic and alpine biodiversity: patterns, causes and ecosystem consequences. Trends Ecol Evol 9:45-47

Clark JM, Kenna MP (2010) Lawn and turf: management and environmental issues of turfgrass pesticides. Academic Press, Boston, Massachusetts

Cornelissen B, Neumann P, Schweiger O (2019) Global warming promotes biological invasion of a honey bee pest. Glob Chang Biol 25:3642-3655

D' Amen M, Mod HK, Gotelli NJ, Guisan A (2018) Disentangling biotic interactions, environmental filters, and dispersal limitation as drivers of species co-occurrence. Ecography 41:1233-1244

Delbac L, Rusch A, Binet D, Thiéry D (2020) Seasonal variation of Drosophilidae communities in viticultural landscapes. Basic Appl Ecol 48:83-91

Donatelli M, Magarey RD, Bregaglio S, Willocquet L, Whish JP, Savary S (2017) Modelling the impacts of pests and diseases on agricultural systems. Agric Syst 155:213-224

Eschtruth AK, Battles JJ (2008) Deer herbivory alters forest response to canopy decline caused by an exotic insect pest. Ecol Appl 18:360-376

Eyles A, Bonello P, Ganley R, Mohammed C (2010) Induced resistance to pests and pathogens in trees. New Phytol 185:893-908

Fei S, Morin RS, Oswalt CM, Liebhold AM (2019) Biomass losses resulting from insect and disease invasions in US forests. PNAS USA 116:17371-17376

Forister ML, Dyer LA, Singer MS, Stireman JO III, Lill JT (2012) Revisiting the evolution of ecological specialization, with emphasis on insect-plant interactions. Ecology 93:981-991

Frago E, Dicke M, Godfray HCJ (2012) Insect symbionts as hidden players in insect-plant interactions. Trends Ecol Evol 27:705-711

Freilich MA, Wieters E, Broitman BR, Marquet PA, Navarrete SA (2018) Species cooccurrence networks: can they reveal trophic and non-trophic interactions in ecological communities? Ecology 99:690-699

Gallardo B, Zieritz A, Aldridge DC (2015) The importance of the human footprint in shaping the global distribution of terrestrial, freshwater and marine invaders. PLoS One 10:e0125801

González-Moreno P, Diez JM, Richardson DM, Vilà M (2015) Beyond climate: disturbance niche shifts in invasive species. Glob Ecol Biogeogr 24:360-370

Grabherr G (2009) Biodiversity in the high ranges of the Alps: ethnobotanical and climate change perspectives. Glob Environ Change 19:167-172

Griffith DM, Veech JA, Marsh CJ (2016) Cooccur: probabilistic species cooccurrence analysis in R. J Stat Softw 69:1-17

Grünig M, Mazzi D, Calanca P, Karger DN, Pellissier L (2020) Crop and forest pest metawebs shift towards increased linkage and suitability overlap under climate change. Comm Biol 3:1-10

Guo Q, Fei S, Potter KM, Liebhold AM, Wen J (2019) Tree diversity regulates forest pest invasion. PNAS 116:7382-7386

Gurr GM, Wratten SD, Landis DA, You M (2017) Habitat management to suppress pest populations: progress and prospects. Annu Rev Entomol 62:91-109

Guyot V, Castagneyrol B, Vialatte A, Deconchat M, Jactel H (2016) Tree diversity reduces pest damage in mature forests across Europe. Biol Lett 12:20151037

Guyot V, Jactel H, Imbaud B, Burnel L, Castagneyrol B, Heinz W, Deconchat M, Vialatte A (2019) Tree diversity drives associational resistance to herbivory at both forest edge and interior. Ecol Evol 9:9040-9051
Hill MP, Gallardo B, Terblanche JS (2017) A global assessment of climatic niche shifts and human influence in insect invasions. Glob Ecol Biogeogr 26:679689

Hill MP, Binns M, Umina PA, Hoffmann AA, Macfadyen S (2019) Climate, human influence and the distribution limits of the invasive European earwig, Forficula auricularia, in Australia. Pest Manag Sci 75:134-143

Horner-Devine MC, Silver JM, Leibold MA, Bohannan BJ, Colwell RK, Fuhrman JA, Green JL, Kuske CR, Martiny JBH, Muyzer G, Øvreås L, Reysenbach AL, Smith VH (2007) A comparison of taxon co-occurrence patterns for macro-and microorganisms. Ecology 88:1345-1353

Hou X (2001) Vegetation atlas of China. Chinese academy of science, the editorial Board of Vegetation map of China. Scientific Press, Beijing

Jactel H, Koricheva J, Castagneyrol B (2019) Responses of forest insect pests to climate change: not so simple. Curr Opin Insect Sci 35:103-108

Jactel H, Moreira X, Castagneyrol B (2021) Tree diversity and forest resistance to insect pests: patterns, mechanisms, and prospects. Annu Rev Entomol 66: 277-296

Ji L, Wang Z, Wang X, An L (2011) Forest insect pest management and forest management in China: an overview. Environ Manag 48:1107-1121

Johnson DM, Büntgen U, Frank DC, Kausrud K, Haynes KJ, Liebhold AM, Esper J, Stenseth NC (2010) Climatic warming disrupts recurrent Alpine insect outbreaks. PNAS 107:20576-20581

Karger DN, Conrad O, Böhner J, Kawohl T, Kreft H, Soria-Auza RW, Zimmermann $\mathrm{NE}$, Linder HP, Kessler M (2017) Climatologies at high resolution for the earth's land surface areas. Sci Data 4:170122

Klapwijk MJ, Bylund H, Schroeder M, Björkman C (2016) Forest management and natural biocontrol of insect pests. Forestry 89:253-262

Kulhanek SA, Leung B, Ricciardi A (2011) Using ecological niche models to predict the abundance and impact of invasive species: application to the common carp. Ecol Appl 21:203-213

Lehmann P, Ammunét T, Barton M, Battisti A, Eigenbrode SD, Jepsen JU, Kalinkat G, Neuvonen S, Niemelä P, Terblanche JS, Økland B, Björkman C (2020) Complex responses of global insect pests to climate warming. Front Ecol Environ 18:141-150

Lewis RJ, Szava-Kovats R, Pärtel M (2016) Estimating dark diversity and species pools: an empirical assessment of two methods. Method Ecol Evol 7:104-113

Lewis RJ, de Bello F, Bennett JA, Fibich P, Finerty GE, Götzenberger L, Hiiesalu I, Kasari L, Lepš J, Májeková M, Mudrák O, Riibak K, Ronk A, Rychtecká T, Vitová A, Pärtel M (2017) Applying the dark diversity concept to nature conservation. Conserv Biol 31:40-47

Logan JA, Régnière J, Powell JA (2003) Assessing the impacts of global warming on forest pest dynamics. Front Ecol Environ 1:130-137

Lövei GL, Sunderland KD (1996) Ecology and behavior of ground beetles (Coleoptera: Carabidae). Annu Rev Entomol 41:231-256

Lu M, Miller DR, Sun JH (2007) Cross-attraction between an exotic and a native pine bark beetle: a novel invasion mechanism? PLoS One 2:e1302

Magarey RD, Isard SA (2017) A troubleshooting guide for mechanistic insect pest forecast models. J Integr Pest Manag 8:1-7

Maron JL, Vilà M (2001) When do herbivores affect plant invasion? Evidence for the natural enemies and biotic resistance hypotheses. Oikos 95:361-373

Milosavljević I, Esser AD, Crowder DW (2016) Effects of environmental and agronomic factors on soil-dwelling pest communities in cereal crops. Agric Ecosyst Environ 225:192-198

Minckley TA, Shriver RK, Shuman B (2012) Resilience and regime change in a southern Rocky Mountain ecosystem during the past 17000 years. Ecol Monogr 82:49-68

Müller-Schärer H, Schaffner U, Steinger T (2004) Evolution in invasive plants: implications for biological control. Trends Ecol Evol 19:417-422

Nunez-Mir GC, Liebhold AM, Guo Q, Brockerhoff EG, Jo I, Ordonez K, Fei S (2017) Biotic resistance to exotic invasions: its role in forest ecosystems, confounding artifacts, and future directions. Biol Invas 19:3287-3299

Pärtel M, Szava-Kovats R, Zobel M (2013) Community completeness: linking local and dark diversity within the species pool concept. Folia Geobot 48:307-317

Pautasso M, Döring TF, Garbelotto M, Pellis L, Jeger MJ (2012) Impacts of climate change on plant diseases_opinions and trends. Eur J Plant Pathol 133:295313

Pearson DE, Ortega YK, Eren Ö, Hierro JL (2018) Community assembly theory as a framework for biological invasions. Trends Ecol Evol 33:313-325

Poeydebat C, Castagneyrol B, van Halder I, Jactel H (2021) Changes in host basal area explain associational resistance of mixed forests to primary pests. For Ecol Manag 495:119374 
Prather CM, Laws AN (2018) Insects as a piece of the puzzle to mitigate global problems: an opportunity for ecologists. Basic Appl Ecol 26:71-81

Rasche L, Taylor RA (2019) EPIC-GILSYM: Modelling crop-pest insect interactions and management with a novel coupled crop-insect model. J Appl Ecol 56: 2045-2056

Régnière J, Powell J, Bentz B, Nealis V (2012) Effects of temperature on development, survival and reproduction of insects: experimental design, data analysis and modeling. J Insect Physiol 58:634-647

Ronk A, Szava-Kovats R, Zobel M, Pärtel M (2017) Observed and dark diversity of alien plant species in Europe: estimating future invasion risk. Biodivers Conserv 26:899-916

Sallé A, Nageleisen LM, Lieutier F (2014) Bark and wood boring insects involved in oak declines in Europe: current knowledge and future prospects in a context of climate change. For Ecol Manag 328:79-93

Sanderson EW, Jaiteh M, Levy MA, Redford KH, Wannebo AV, Woolmer G (2002) The human footprint and the last of the wild: the human footprint is a global map of human influence on the land surface, which suggests that human beings are stewards of nature, whether we like it or not. Bioscience 52:891-904

Savary S, Horgan F, Willocquet L, Heong KL (2012) A review of principles for sustainable pest management in rice. Crop Prot 32:54-63

Sax DF, Stachowicz JJ, Brown JH, Bruno JF, Dawson MN, Gaines SD, Grosberg RK, Hastings A, Holt RD, Mayfield MM, O'Connor MI, Rice WR (2007) Ecological and evolutionary insights from species invasions. Trends Ecol Evol 22:465471

Schneider L, Comte V, Rebetez M (2021) Increasingly favourable winter temperature conditions for major crop and forest insect pest species in Switzerland. Agric For Meteorol 298:108315

Sequeira R, Mackauer M (1992) Nutritional ecology of an insect host-parasitoid association: the pea aphid-Aphidius ervi system. Ecology 73:183-189

Shah AA, Dillon ME, Hotaling S, Woods HA (2020) High elevation insect communities face shifting ecological and evolutionary landscapes. Curr Opin Insect Sci 41:1-6

Tiberi R, Branco M, Bracalini M, Croci F, Panzavolta T (2016) Cork oak pests: a review of insect damage and management. Ann For Sci 73:219-232

Veech JA (2013) A probabilistic model for analysing species co-occurrence. Glob Ecol Biogeogr 22:252-260

Venette RC (2017) Climate analyses to assess risks from invasive forest insects: simple matching to advanced models. Curr For Rep 3:255-268

Wang CJ, Wang R, Yu CM, Dang XP, Sun WG, Li QF, Wang XT, Wan JZ (2021) Risk assessment of insect pest expansion in alpine ecosystems under climate change. Pest Manag Sci 77:3165-3178

Waring KM, O'Hara KL (2005) Silvicultural strategies in forest ecosystems affected by introduced pests. For Ecol Manag 209:27-41

Worner SP, Gevrey M (2006) Modelling global insect pest species assemblages to determine risk of invasion. J Appl Ecol 43:858-867

Zhang X, Sun S, Yong S, Zhou Z, Wang R (2007) Vegetation map of the People's republic of China (1:1000000). Geology Publishing House, Beijing

\section{Submit your manuscript to a SpringerOpen ${ }^{\circ}$ journal and benefit from:}

- Convenient online submission

- Rigorous peer review

- Open access: articles freely available online

- High visibility within the field

- Retaining the copyright to your article

Submit your next manuscript at $\boldsymbol{\nabla}$ springeropen.com 